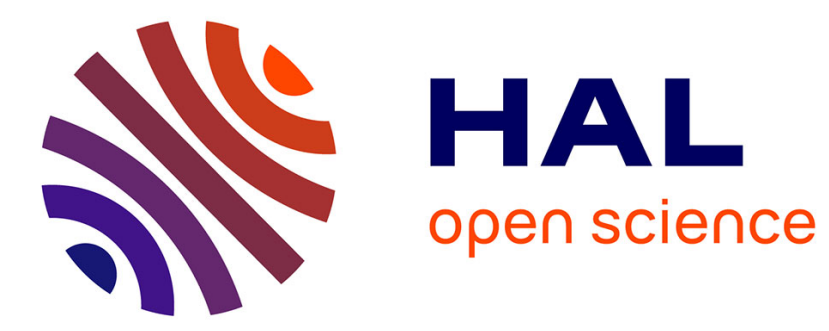

\title{
Nanoparticle size influences the proliferative responses of lymphocyte subpopulations
}

Xavier Le Guével, Francisca Palomares, María Torres, Miguel Blanca, Tahia Fernandez, Cristobalina Mayorga

\section{- To cite this version:}

Xavier Le Guével, Francisca Palomares, María Torres, Miguel Blanca, Tahia Fernandez, et al.. Nanoparticle size influences the proliferative responses of lymphocyte subpopulations. RSC Advances, 2015, 5 (104), pp.85305-85309. 10.1039/c5ra16164a . hal-02338001

\section{HAL Id: hal-02338001 \\ https://hal.science/hal-02338001}

Submitted on 29 Oct 2019

HAL is a multi-disciplinary open access archive for the deposit and dissemination of scientific research documents, whether they are published or not. The documents may come from teaching and research institutions in France or abroad, or from public or private research centers.
L'archive ouverte pluridisciplinaire HAL, est destinée au dépôt et à la diffusion de documents scientifiques de niveau recherche, publiés ou non, émanant des établissements d'enseignement et de recherche français ou étrangers, des laboratoires publics ou privés. 


\section{PAPER}

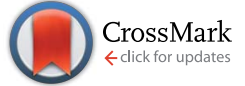

Cite this: RSC Adv., 2015, 5, 85305

Received 11th August 2015

Accepted 2nd October 2015

DOI: $10.1039 / \mathrm{c} 5 \mathrm{ra16164a}$

www.rsc.org/advances

\section{Nanoparticle size influences the proliferative responses of lymphocyte subpopulations $\uparrow$}

\author{
Xavier le Guével, ${ }^{* a}$ Francisca Palomares, ${ }^{\text {b }}$ Maria J. Torres, ${ }^{\text {bc }}$ Miguel Blanca, ${ }^{\text {bc }}$ \\ Tahia D. Fernandez ${ }^{\mathrm{b}}$ and Cristobalina Mayorga ${ }^{\mathrm{bc}}$ \\ $12 \mathrm{~nm}$ gold nanoparticles induce cell mediated responses accompanied by inflammatory natural killer cell \\ stimulation, whereas $2 \mathrm{~nm}$ gold nanoparticles are more efficiently uptaken without inducing dendritic cell \\ maturation or lymphocyte proliferation.
}

The use of engineered nanoparticles for immunotherapy has been extensively investigated, notably towards the development of novel vaccines. ${ }^{1-5}$ By tailoring their physicochemical properties such as size, shape, and surface chemistry, nanoparticles are able to positively or negatively modulate immune responses via antigen presenting cells (APCs). ${ }^{2-4,6,7}$ This strategy promises the development of novel nanovaccines that are able to modify adaptive immune responses for the treatment of cancer or autoimmune diseases. ${ }^{6,8-10}$ For example, increased nanoparticle surface hydrophobicity has been shown to progressively induce acute inflammation in both in vitro and in vivo models. ${ }^{7}$ Nanoparticle shape can also affect immune responses, for example rod and star shapes elicit enhanced immune responses, although their clearance may have toxic effects. ${ }^{11,12}$ Another parameter that has been studied is the influence of spherical particle sizes from $40 \mathrm{~nm}$ to one micron with larger nanoparticles favouring the induction of cell-mediated responses and a higher cell uptake for particles smaller than $500 \mathrm{~nm}^{.13,14}$

In this study we chose gold particles with two different sizes at the lower end of the nanosize window: $2 \mathrm{~nm}$ so-called nanoclusters (NCs) ${ }^{15,16}$ and $12 \mathrm{~nm}$ nanoparticles (NPs) both protected by the same glutathione (GSH) tripeptide ligand. GSH is an antioxidant which offers the advantage of improving the colloidal stability of particles in complete medium, while its free carboxyl groups allow molecules to be conjugated onto the surface. ${ }^{18}$ Dendritic cells (DCs), an important type of APC, modulate both effector and tolerance responses by presenting MHC Class II-bound antigens to T lymphocytes while secreting co-stimulatory factors that depend on their maturational

${ }^{a}$ Therapeutic Nanosystem, The Andalusian Centre for Nanomedicine and Biotechnology, BIONAND, Málaga, Spain.E-mail: xleguevel@bionand.es ${ }^{b}$ Research Laboratory and Allergy Service, IBIMA, Regional University Malaga Hospital, UMA, Málaga, Spain

${ }^{c}$ Allergy Service, Regional University Malaga Hospital, UMA, Málaga, Spain

$\dagger$ Electronic supplementary information (ESI) available: Synthesis and characterisation of the nanomaterial, experimental protocols, fluorescence microscopy, cytotoxicity and cytokine experiments. See DOI: $10.1039 / \mathrm{c} 5 \mathrm{ra} 16164 \mathrm{a}$ state. ${ }^{19-21}$ Our aim was to determine if size $(<15 \mathrm{~nm})$ affects particle uptake by dendritic cells, and whether it alters their effects on the immunological system as judged by changes to DC maturation and the inflammatory responses of different lymphocyte subpopulations. DC maturation was evaluated by cell surface markers and cytokine secretion, while inflammatory responses was followed by looking at the proliferation of different lymphocyte subpopulations including $\mathrm{CD} 4^{+}$and $\mathrm{CD} 8^{+}$ $\mathrm{T}$ and Natural Killer (NK) cells, as well as cytokine production.

Particles synthesis was conducted in aqueous solution using gold salt and GSH, with sodium borohydride also used for the larger particles (see ESI for details $\dagger$ ). Particle size was determined by dynamic light scattering (Fig. 1a) and electron microscopy (Fig. S1 $\dagger$ ) indicating high monodispersity for NCs $(\varnothing \sim 2 \mathrm{~nm})$ and NPs $(\varnothing \sim 12 \mathrm{~nm})$. We used thermal analysis to estimate ligand content per particle (based on the ligand's organic moiety) finding around $56 \%$ and $19 \%$ for NCs and NPs, respectively. No significant aggregation of NCs or NPs was observed after incubation in complete medium (RPMI1640 + $10 \%$ serum) for 48 hours. Absorbance analysis revealed that NPs possess the typical plasmon band at $520 \mathrm{~nm}$. In contrast, NCs a

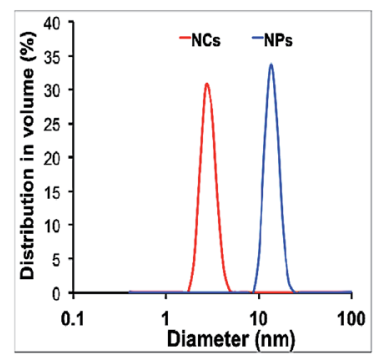

b

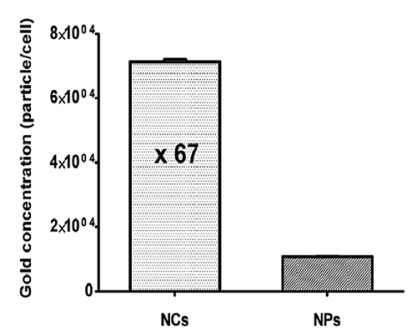

Fig. 1 (a) Size analysis by dynamic light scattering of GSH ligandstabilised NCs and NPs in aqueous solution. (b) Inductively coupled plasma high-resolution mass spectrometry (ICP-HRMS) measurements of DCs incubated with NCs or NPs $\left(10 \mu \mathrm{g} \mathrm{mL}^{-1}\right.$ in complete medium) for 48 hours. 
exhibited strong UV absorption (Fig. S2 $\dagger$ ) and intense photoluminescence in the orange-red window $\left(\lambda_{\max }=610 \mathrm{~nm}\right)^{22}$ (Fig. S3†), which originate from the strong quantum confinement seen in species of this size and metal-ligand interactions..$^{23-26}$

NC and NP cytotoxicity was evaluated in human monocytederived dendritic cells (DCs) via specific Live/Dead cell staining and flow cytometry. Incubation for 48 hours with concentrations up to $25 \mu \mathrm{g} \mathrm{mL} \mathrm{m}^{-1}$ of NCs, NPs or equivalent concentrations of free GSH ligand had no significant effect on cytotoxicity compared to non-treated cells (Fig. S4†). Cellular particle uptake was quantified by inductively coupled plasma high-resolution mass spectrometry (ICP-HRMS) after incubating DCs with NCs or NPs $(10 \mu \mathrm{g}$ gold per $\mathrm{mL})$ for 48 hours (Fig. 1b). We found that NC uptake in terms of gold particles per cell was 67 times higher than that of NPs, indicating highly efficient internalisation of NCs into DCs. This observation is in agreement with previous studies showing stronger uptake of small particles, most likely related to their high diffusion capacity. ${ }^{27,28}$ The internalisation of NCs and NPs in the cytoplasm and close to the membrane could be readily observed by the presence of dark accumulations under bright-field illumination, and by photoluminescent emissions upon two-photon excitation $\left(\lambda_{\text {exc. }}=720 \mathrm{~nm}\right)$ (Fig. S5 $\dagger$ ).

One of the first response steps in the immune response to an antigen by a dendritic cell is its maturation. Mature DCs are characterised by the loss of their ability to internalise antigens, while upregulating MHC Class II molecules and co-stimulatory factors such as CD80 and CD86, thereby acquiring the capacity to present antigens to naïve T-cells and inducing different immunological responses. ${ }^{29-31}$ Thus, to understand how particle a

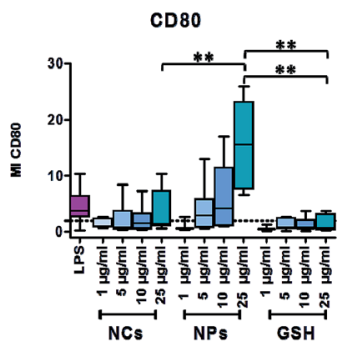

CD86

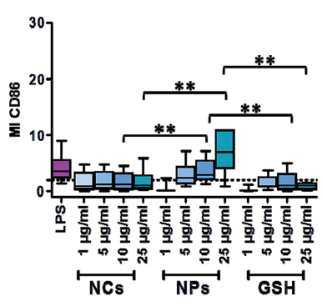

b
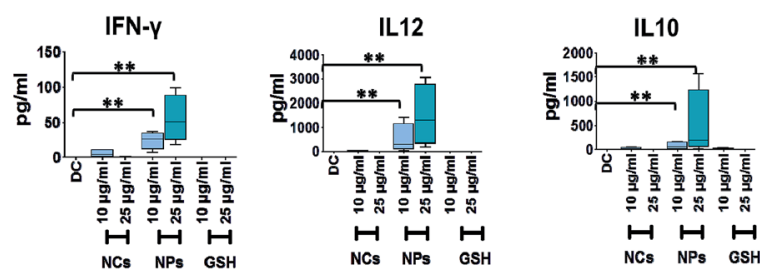

Fig. 2 (a) Maturation status (CD80 and CD86 markers) expressed as a maturation index (MI), and (b) cytokine secretion* (IFN- $\gamma$, IL12, IL10) of DCs incubated with NCs, NPs, free GSH (1 to $25 \mu \mathrm{g} \mathrm{mL} \mathrm{m}^{-1}$ in complete medium) and LPS (lipopolysaccharide) as positive control for $48 \mathrm{~h}$. * - tested at 10 and $25 \mu \mathrm{g} \mathrm{mL}{ }^{-1}$ of NCs, NPs, or eq. conc. of free GSH. Statistical comparisons were performed using the Wilcoxon test for related samples. The Bonferroni correction was applied for comparison of three groups. Statistical differences were considered significant when $p<0.025$ size might affect DC-mediated immune responses, we incubated immature DCs with NCs and NPs (1 to $25 \mu \mathrm{g} \mathrm{mL}{ }^{-1}$ of gold in complete medium) for 48 hours. The maturational status of DCs was then evaluated using flow cytometry-based detection of CD80 and CD86 surface antigens. Positive (lipopolysaccharide; LPS) and negative (free GSH ligand in eq. ligand concentration) controls were also included. Results depicted in Fig. 2a show that incubation with NPs significantly increased the expression of both CD80 and CD86 in a dose dependant manner, suggesting the induction of DC maturation. In contrast, no DC maturation i.e. no increase in expression above the $\mathrm{MI}>2$ threshold, was seen for cells cultured in the presence of NCs or with free ligand alone. We were surprised to observe no significant increase in DC maturation following incubation with NCs, especially as they were more strongly uptaken than NPs. Recent studies have shown that particle uptake does not always correlate with functional changes in human dendritic cells in vitro. ${ }^{32,33}$ Dissimilarities between the two classes of particle might be related to differences in the endocytic pathways involved in their uptake. Further studies will be required to understand the molecular basis for the different interactions between DCs and NCs/NPs.

DC maturation tends to induce high levels of MHC molecules and the secretion of sets of cytokines that play a key role in activating naïve $\mathrm{T}$ cells and the launch of primary immune responses. ${ }^{8}$ To further characterise DC maturation following incubation with NPs or NCs, we measured the pattern of cytokine release into the culture supernatant in each case. Our analysis of cytokine production (IL12, IFN $\gamma$, IL4, IL13, IL10, IL17), depicted in Fig. $2 \mathrm{~b}$ and $\mathrm{S6}, \uparrow$ detected significant increases in IL12, IFN $\gamma$ and IL10 in response to NPs, in a dose dependent manner. Elevated expression of IL12 and IFN $\gamma$ suggest that NPs induce an inflammatory DC response ${ }^{20}$ while no significant cytokine production was detected using NCs or free ligand consistent with the absence of DC maturation following these treatments.

Our finding that particle size affects DC maturation suggests that it may also affect subsequent steps in the immunological response, where mature DCs interact with lymphocyte subpopulations. To examine this possibility we examined how DCs incubated with NCs or NPs can subsequently induce changes in lymphocyte proliferation and activity in terms of cytokine production. Different $\mathrm{T}$ lymphocyte and $\mathrm{NK}$ cell subpopulations have been reported to shape immunological responses in different ways. $\mathrm{T}$ helper cells can be divided into Th1, Th2, Th17 and Treg subpopulations depending on their cytokine production. ${ }^{34}$ Th1 cells have been implicated in responses to infectious and inflammatory disorders. ${ }^{35} \mathrm{Th} 2$ cells are essential for the induction of allergy and asthma. ${ }^{36}$ Th17 cells are related to neutrophil activation and implicated in several autoimmune diseases. ${ }^{34,36}$ Treg cells are involved in the regulation of inflammatory effector cells. Moreover, two NK cell subpopulations have been described: (i) CD56 ${ }^{\mathrm{dim}}$ cells (the main NK population in peripheral blood) expressing high levels of CD16 and perforin, which mediate cytotoxic activity, and (ii) CD56 $6^{\text {bright }}$ cells usually associated with the inflammatory NK population $^{37}$ that produces high levels of IFN $\gamma .^{38}$ 
In this work, we carried out co-culture experiments where $\mathrm{T}$ and Natural Killer (NK) cell populations were incubated with NC or NP-pre-treated DCs to determine their antigen presenting activity by measuring proliferation and cytokine release. DCs were pre-incubated with NCs, NPs or free ligand at different concentrations ( 1 to $25 \mu \mathrm{g}$ gold per $\mathrm{mL}$ in complete medium or equivalent ligand concentrations), washed and then co-cultured over 6 days. No significant cytotoxicity was observed regardless of the particle concentration used (Fig. S4†). Lymphocyte proliferation, expressed as a proliferation index (PI), was evaluated by measuring the frequency of cells with reduced levels of a fluorescent tracer (CFSE ${ }^{\text {dim }}$ cells) together with specific subpopulation markers. Results indicated increases in the PI of T lymphocytes $\left(\mathrm{CD}^{+} \mathrm{CFSE}^{\mathrm{dim}}\right)$, T helper $\left(\mathrm{CD} 4^{+} \mathrm{CFSE}^{\mathrm{dim}}\right)$ and $\mathrm{NK}$ $\left(\mathrm{CD}^{+} \mathrm{CFSE}^{\mathrm{dim}}\right)$ cells following incubation with high NP concentrations (Fig. 3a). No proliferative response increases (PI $<2)$ were detected for cytotoxic $\mathrm{T}$ cells $\left(\mathrm{CD}^{+}\right)$incubated with NP-treated DCs, or following co-culture with DCs treated with NCs or free GSH.

To better understand the immunological effect of NPstimulated DCs, we set out to identify the different subpopulations involved in $\mathrm{T}$ and NK cell proliferation. Our results indicate non-specific proliferative responses by Treg and Th17 populations after stimulation with the different particles since no differences in their proliferative response were found compared to GSH-stimulated cells (Fig. S7†).

The production of IFN $\gamma$ by lymphocytes not secreting IL4 and IL13 (Fig. S6 $†$ ) following the presentation of NP pre-treated DCs could also be associated with the induction of a proliferative CD4 sub-population corresponding to a cell-mediated
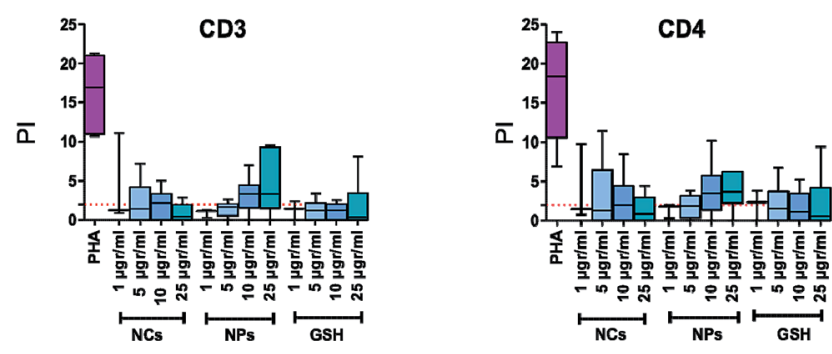
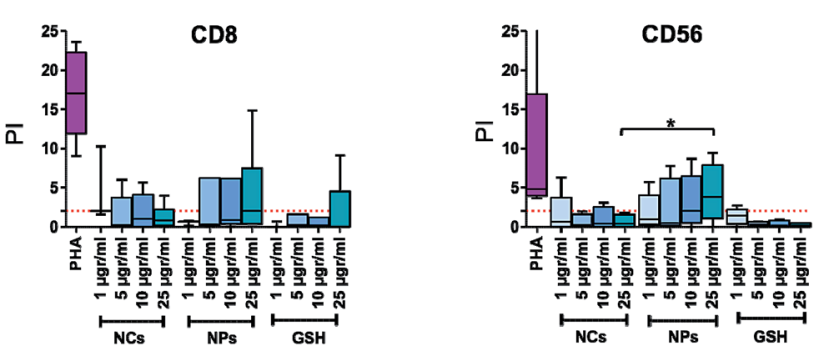

Fig. 3 Proliferative responses of different lymphocyte subpopulations (CD3, CD4, CD8, and CD56 markers), expressed as a proliferation index (PI), with Peripheral Blood Mononuclear Cells (PBMCs) + DCs incubated with NCs, NPs or GSH (1 to $25 \mu \mathrm{g} \mathrm{mL}^{-1}$ in complete medium) for 6 days. Statistical comparisons were performed using the Wilcoxon test for related samples. The Bonferroni correction was applied for comparison of three groups. Statistical differences were considered significant when $p<0.025$. response (Th1) and matches the cytokine release observed during NP-induced DC maturation.

Regarding NK cells, significantly increased proliferation of the CD56 ${ }^{\text {bright }}$ NK subpopulation combined with elevated IFN $\gamma$ production was observed in response to co-culture with NPtreated DCs in a dose dependent manner (Fig. 4a and b). Importantly, there was no increase in granzyme B secretion, a cytotoxic mediator released from cytoplasmic granules in cytotoxic $\mathrm{T}$ and NK cells, following NP-treated DC co-culture (Fig. 4c). These two observations are consistent with the presence of high levels of inflammatory NK cells (CD56 ${ }^{\text {bright }}$ ).

Our lymphocyte proliferative data indicate that the increase in Th1 lymphocytes and CD56 $6^{\text {bright }} \mathrm{NK}$ cells is related to the production of IFN $\gamma$ and IL12 combined with undetectable levels of IL4 and IL13 (Fig. 2b and S6†) following NP stimulation. These results suggest that NP treatment promotes innate immunity-type responses from NK cells.

The results obtained in this work are in agreement with a previous study suggesting crosstalk between innate and adaptive immune systems involving interactions between DCs and NK cells. ${ }^{39}$ This concept is supported by the demonstration that DCs can activate NK cells, while activated NK cells can influence DC maturation or direct their cytotoxiceffects specifically towards immature DCs, which would hamper tolerant responses. ${ }^{\mathbf{4 0 , 4 1}}$ Thus, crosstalk between DC and NK cell populations is likely to be a key factor in influencing the balance between tolerant and immunologic responses.

By employing the same surface chemistry for both particles, this study clearly demonstrates the strong influence of particle

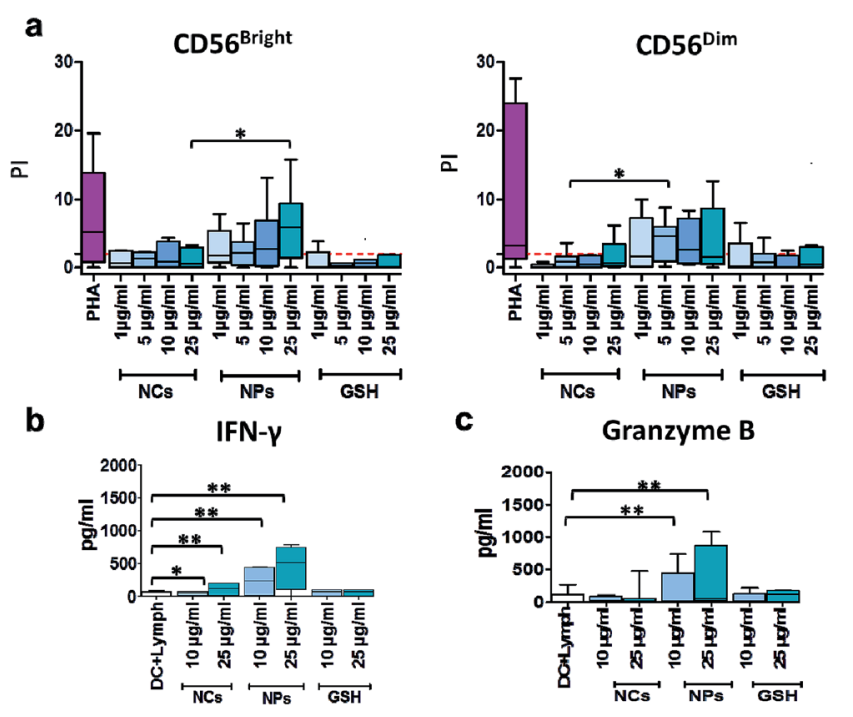

Fig. 4 (a) Proliferative responses of different lymphocyte NK subpopulations (CD56 ${ }^{\text {dim }}$ and CD56 ${ }^{\text {bright }}$ cells); (b) cytokine INFr secretion levels during the proliferative lymphocyte experiments*, (c) granzyme B assay on peripheral blood lymphocytes*. Proliferation positive control: PHA: phytohemagglutinin. * only at 10 and $25 \mu \mathrm{g}$ $\mathrm{mL}^{-1}$ of NCs, NPs, and eq. free GSH. Statistical comparisons were performed using the Wilcoxon test for related samples. The Bonferroni correction was applied for comparison of three groups. Statistical differences were considered significant when $p<0.025$. 
size on DC uptake, DC maturation, the proliferative response of $\mathrm{T}$ lymphocytes and the presence of inflammatory NK cells.

The ultra-small particles (NCs, $\varnothing \sim 2 \mathrm{~nm}$ ) were efficiently uptaken by DCs but did not induce maturation or lymphocyte proliferation. These observations seem to agree with studies demonstrating high passive targeting and clearance of NCs stabilised with GSH. ${ }^{17,42}$ The presence of functional GSH carboxyl groups on the NC surface should enable the conjugation of biomolecules such as antigens and, in the absence of carrier-associated immunogenic reactions, represents a good candidate antigen delivery system. In contrast, the slightly bigger nanoparticles (NPs, $\varnothing \sim 12 \mathrm{~nm}$ ) caused DC maturation and $\mathrm{T}$ lymphocyte proliferation associated with cell-mediated immunity-type responses and the production of inflammatory NK cells in a dose dependent manner. These results are of considerable interest as this subpopulation is a potential target for anti-tumour immunotherapy, inflammatory response limitation and the treatment of autoimmune disorders..$^{43}$ Indeed, this NK cell sub-type represents a relatively small proportion of Peripheral Blood Mononuclear Cells (PBMCs) but presents the advantage of being one of the most efficient cytokine producers ${ }^{37}$ and is able to shape the adaptive response. Indeed, Caliguri et al. undertook a comprehensive investigation of the role of NK sub-types, demonstrating the unique innate immunoregulatory role of the CD56 ${ }^{\text {bright }}$ subpopulation by producing specific types of cytokines. ${ }^{20}$ Because lowered NK activity in peripheral blood has been associated with elevated cancer risk in patients, strategies involving enhancement of NK cells for anti-tumour treatment are currently being investigated. ${ }^{\mathbf{4 4 , 4 5}}$

As previously discussed by Drobrovolskaia et al.,${ }^{46}$ it remains difficult to demonstrate clear relationships between the physicochemical properties of particles and their effects on immune responses due to the complex interactions between cytokines and numerous other cellular processes such as multiple cell uptake mechanisms. Different particle types have been shown to elicit Th1 responses but the contribution of inflammatory NK cells accompanied by high IFN $\gamma$ levels in response to $12 \mathrm{~nm}$ nanoparticles potentially opens new avenues for immunotherapeutic treatments of cancer or infections.

\section{Conclusions}

In summary, we have shown how particle size in a narrow size range ( 1 to $15 \mathrm{~nm}$ ) strongly influences cell uptake and immune responses with ultra-small size $(<2 \mathrm{~nm})$ leading to high cellular uptake without DC maturation and therefore lymphocyte proliferation. In contrast, bigger particles $(12 \mathrm{~nm})$ elicited DC maturation with a cell-mediated immunity pattern (Th1) and the proliferation of $\mathrm{T}$ helper lymphocytes in a concentration dependent manner. Moreover, we found that $12 \mathrm{~nm}$ NPs induced the proliferation of inflammatory NK cells with high levels of pro-inflammatory cytokine IFN $\gamma$ secretion, suggesting that it might represent a tool for shaping and influencing adaptive immunity to fight cancer or infectious diseases. Our results underline the importance of examining different particle sizes in the 1-15 $\mathrm{nm}$ nanometric window in order to fine tune their effects on the immune system.

\section{Acknowledgements}

This work was supported by the Instituto de Salud Carlos III (ISCII) as part of project No. CP12/03310 co-financed by European regional development Fund (ERDF). FIS-Thematic Networks and Co-operative Research Centres: RIRAAF (RD012/ 0013), Junta de Andalucía (CTS-7433), and ISCIII (PI12/02481; PI12/02529), Nicolas Monardes Program (C-0044-2012 SAS 2013). Xavier Le Guevel would like to thank Daniel Sierra for the nanocluster synthesis, Rocio Gonzales Montero for the ICP analysis, and John Pearson (BIONAND Nanoimaging Unit) for the optical microscopy analysis and critical reading of the manuscript. We thank Dr Hua Jiang for the HRTEM characterisation performed in the Nanomicroscopy Center at Aalto University.

\section{Notes and references}

1 B. S. Zolnik, Á. González-Fernández, N. Sadrieh and M. A. Dobrovolskaia, Endocrinology, 2010, 151, 458-465.

2 J. A. Hubbell, S. N. Thomas and M. A. Swartz, Nature, 2009, 462, 449-460.

3 M. A. Dobrovolskaia and S. E. McNeil, Nat. Nanotechnol., 2007, 2, 469-478.

4 J. de Souza Rebouças, I. Esparza, M. Ferrer, M. L. Sanz, J. M. Irache and C. Gamazo, J. Biomed. Biotechnol., 2012, 2012, 1-13.

5 L. J. Cruz, P. J. Tacken, F. Rueda, J. C. Domingo, F. Albericio and C. G. Figdor, Methods Enzymol., 2012, 509, 143-163.

6 J. C. Aguilar and E. G. Rodríguez, Vaccine, 2007, 25, 37523762.

7 D. F. Moyano, M. Goldsmith, D. J. Solfiell, D. LandesmanMilo, O. R. Miranda, D. Peer and V. M. Rotello, J. Am. Chem. Soc., 2012, 134, 3965-3967.

8 M. Kreutz, P. J. Tacken and C. G. Figdor, Blood, 2013, 121, 2836-2844.

9 I. Mellman and R. M. Steinman, Cell, 2001, 106, 255-258.

10 M. Zaman, M. F. Good and I. Toth, Methods, 2013, 60, 226231.

11 X. Huang, L. Li, T. Liu, N. Hao, H. Liu, D. Chen and F. Tang, ACS Nano, 2011, 5, 5390-5399.

12 J. A. Champion, Y. K. Katare and S. Mitragotri, J. Controlled Release, 2007, 121, 3-9.

13 S. Tomić, J. Dokić, S. Vasilijić, N. Ogrinc, R. Rudolf, P. Pelicon, D. Vučević, P. Milosavljević, S. Janković, I. Anžel, J. Rajković, M. S. Rupnik, B. Friedrich and M. Čolić, PLoS One, 2014, 9, e96584.

14 L. W. Zhang, W. Bäumer and N. A. Monteiro-Riviere, Nanomedicine, 2011, 6, 777-791.

15 X. Le Guevel, C. Spies, N. Daum, G. Jung and M. Schneider, Nano Res., 2012, 5, 379-387.

16 J. Xie, Y. Zheng and J. Y. Ying, J. Am. Chem. Soc., 2009, 131, 888-889.

17 X. D. Zhang, Z. Luo, J. Chen, S. Song, X. Yuan, X. Shen, H. Wang, Y. Sun, K. Gao, L. Zhang, S. Fan, D. T. Leong, M. Guo and J. Xie, Sci. Rep., 2015, 5, 1-7. 
18 R. D. Vinluan, J. Liu, C. Zhou, M. Yu, S. Yang, A. Kumar, S. Sun, A. Dean, X. Sun and J. Zheng, ACS Appl. Mater. Interfaces, 2014, 6, 11829-11833.

19 R. M. Steinman, D. Hawiger, K. Liu, L. Bonifaz, D. Bonnyay, K. Mahnke, T. Iyoda, J. Ravetch, M. Dhodapkar, K. Inaba and M. Nussenzweig, Ann. N. Y. Acad. Sci., 2003, 987, 15-25.

20 A. K. Abbas and A. H. Sharpe, Nat. Immunol., 2005, 6, 227228.

21 J. Banchereau and R. M. Steinman, Nature, 1998, 392, 245252.

22 X. Le Guevel, V. Trouillet, C. Spies, K. Li, T. Laaksonen, D. Auerbach, G. Jung and M. Schneider, Nanoscale, 2012, 4, 7624-7631.

23 R. Jin, Nanoscale, 2010, 2, 343-362.

24 X. le Guevel, IEEE J. Sel. Top. Quantum Electron., 2014, 20, 6801312.

25 Z. Wu and R. Jin, Nano Lett., 2010, 10, 2568-2573.

26 J. Zheng, C. Zhou, M. Yu and J. Liu, Nanoscale, 2012, 4, 40734083.

27 T. D. Fernández, J. R. Pearson, M. P. Leal, M. J. Torres, M. Blanca, C. Mayorga and X. le Guével, Biomaterials, 2015, 43, 1-12.

28 X. le Guevel, M. Perez Perrino, T. D. Fernandez, P. Palomares, M. J. Torres, M. Blanca, J. Rojo and C. Mayorga, ACS Appl. Mater. Interfaces, 2015, 7, 2094520956.

29 D. Antonios, N. Ade, S. Kerdine-Romer, H. AssafVandecasteele, A. Larange, H. Azouri and M. Pallardy, Toxicol. In Vitro, 2009, 23, 227-234.

30 D. N. Hart, Blood, 1997, 90, 3245-3287.

31 R. Rodriguez-Pena, S. Lopez, C. Mayorga, C. Antunez, T. D. Fernandez, M. J. Torres and M. Blanca, J. Allergy Clin. Immunol., 2006, 118, 949-956.
32 K. Fytianos, L. Rodriguez-Lorenzo, M. J. D. Clift, F. Blank, D. Vanhecke, C. von Garnier, A. Petri-Fink and B. RothenRutishauser, Nanomedicine, 2015, 11, 633-644.

33 E. Seydoux, B. Rothen-Rutishauser, I. M. Nita, S. Balog, A. Gazdhar, P. A. Stumbles, A. Petri-Fink, F. Blank and C. von Garnier, Int. J. Nanomed., 2014, 9, 3885-3902.

34 M. Akdis, O. Palomares, W. van de Veen, M. van Splunter and C. A. Akdis, J. Allergy Clin. Immunol., 2012, 129, 1438-1449.

35 S. Romagnani, Ann. Allergy, Asthma, Immunol., 2000, 85, 921.

36 N. W. Palm, R. K. Rosenstein and R. Medzhitov, Nature, 2012, 484, 465-472.

37 M. A. Cooper, T. A. Fehniger and M. A. Caligiuri, Trends Immunol., 2001, 22, 633-640.

38 J. S. Orange and Z. K. Ballas, Clin. Immunol., 2006, 118, 1-10. 39 T. Walzer, M. Dalod, S. H. Robbins, L. Zitvogel and E. Vivier, Blood, 2005, 106, 2252-2258.

40 P. Chaves, M. J. Torres, A. Aranda, S. Lopez, G. Canto, M. Blanca and C. Mayorga, Allergy, 2010, 65, 1600-1608.

41 G. Ferlazzo, M. Pack, D. Thomas, C. Paludan, D. Schmid, T. Strowig, G. Bougras, W. A. Muller, L. Moretta and C. Münz, Proc. Natl. Acad. Sci. U. S. A., 2004, 101, 1660616611.

42 J. Liu, M. Yu, C. Zhou, S. Yang, X. Ning and J. Zheng, J. Am. Chem. Soc., 2013, 135, 4978-4981.

43 E. Vivier, E. Tomasello, M. Baratin, T. Walzer and S. Ugolini, Nat. Immunol., 2008, 9, 503-510.

44 H. G. Ljunggren and K. J. Malmberg, Nat. Rev. Immunol., 2007, 7, 329-339.

45 S. R. Yoon, T. D. Kim and I. Choi, Exp. Mol. Med., 2015, 47, e141.

46 A. N. Ilinskaya and M. A. Dobrovolskaia, Br. J. Pharmacol., 2014, 171, 3988-4000. 